\title{
Development of the hyoid bone (Os hyoideum) in the one-humped camel (Camelus dromedarius)
}

\section{K.M. Shoghy and A.S. Saber}

Department of Anatomy \& Embryology, Faculty of Vet. Med., Sadat City Branch, Menoufiya University, EGYPT

E-mail: khaled.shoghy@yahoo.com

\section{Abstract}

The hyoid bone can be divided into two parts. The first part supports the tongue and larynx and is regarded as the hyoid apparatus, the July 2012 second part is directed dorsally articulating with the temporal bone and is termed the suspensory apparatus. The anatomy and development of the hyoid bone was previously studied in most mammals; however, in the camel it is still obscure. Therefore, the aim of this study is to follow the development of the hyoid bone in the one humped camel (Camelus dromedarius) from the anatomical and embryological point of view. The results revealed that the hyoid bone develops from eight ossification centers; none of them complete its ossification before birth.There is no separate center for the basihyoid of the hyoid bone of the camel but it is formed by the union of the rostral ends of the thyrohyoids.
Keywords: Hyoid bone, Development, Camel

\section{Introduction}

The hyoid bone (Os hyoideum) is situated chiefly between the vertical parts of the rami of the mandible. Its upper part, however, extends somewhat further back. It is attached to the styloid process of the petrous part of the temporal bone by a rod of cartilage, the tympanohyoid (Hillmann, 1975).

The anatomy and development of the hyoid bone was previously studied in most mammals (Hilloowala, 1975, Koebke, 1978 and Atalgin et al., 2007); however, in the camel it is still obscure.

Therefore, the aim of this study is to follow the development of the hyoid bone in the one humped camel (Camelus dromedarius) from the anatomical and embryological point of view. 


\section{Materials and Methods}

\section{Materials:}

1- Six skulls of camel fetuses of both sexes ranging from 40.5 to 80 $\mathrm{cm}$ CVR length. The gestational stage was estimated on the basis of crown vertebral rump CVR length (El-Wishy et al., 1981). The samples were collected from Cairo and Kom-hamada abattoirs. The fetuses were removed shortly after evisceration and the crown to rump length was measured to the nearest $\mathrm{cm}$. using a measuring band.

2- Four skulls of young and adult camels aged 3 and 7.5 - 8 years were collected from local abattoirs in Sadat city. The age was estimated by dentition according to Rabigliata (1924).

\section{Methods:}

1- The hyoid bones of the fetal skulls were dissected carefully without boiling to view the fine bony structures by using scalpel and toothed and blunt forceps.

2- The hyoid bones of the camel skulls were removed from the skulls by boiling in water, liquid soap and Chlor. Then after, detaching and rinsing, so that a clear view of the fine bony structures was achieved. The hyoid bones were then left to dry at room temperature before further observations.
The examined specimens were photographed by digital camera, Sony 6 mega pixels, Dsc - w 50.

\section{Results}

The hyoid bone (Os hyoideum) of the camel is situated between the two vertical parts of the rami of the mandible. It consists of many parts: The basihyoid, the ceratohyoids, the thyrohyoids, the epihyoids and the stylohyoids. The lingual process is missing in the hyoid bone of the camel. Each part of the hyoid bone is developed from a single ossification center in a cartilaginous form.

\section{At $40.5 \mathrm{~cm}$ CVRL camel fetuses:}

The thyrohyoids, the ceratohyoids and the epihyoids are still in the cartilaginous form while the stylohyoids show ossification in its central part (Figs 1, 2).

The ceratohyoids are short rods which are directed dorsad and rostrad from either end of the body while the epihyoids are twice as long as the ceratohyoids (Figs. 1, 2). The thyrohyoids are short cylindrical rods of cartilage at this stage of development (Figs. 2). The dorsal extremity of the stylohyoid forms two angles; the articular angle which is attached to the tympanohyoid and the muscular angle which is illdistinct at this stage of development (Figs 1, 2). 


\section{At $80 \mathrm{~cm}$ CVRL camel fetuses:}

The ossification spreads to the thyrohyoids, the ceratohyoids and the epihyoids. The thyrohyoids elongate and become thinner and its free ends are still cartilaginous (Figs 3 , 4). The basihyoid is formed by the union of the rostral ends of the thyrohyoids which are still cartilaginous (Figs 4).The stylohyoids are straight and its dorsal extremities enlarge and the articular and the muscular angles become clear (Figs 3, 4).

\section{At 3 years of age of the camel:}

The hyoid bone increases in length and size and each part is still separated from each other by a considerable rod of cartilage (Figs. 5).The free ends of the thyrohyoids are still cartilaginous (Figs. 5, 6). The basihyoid is also still cartilaginous and its dorsal ends have concave facets which articulate with the ventral ends of the ceratohyoids (Figs 6).The stylohyoids are slightly longer than the preceding bones and are curved medialwards. The muscular processes become thickened and rough for muscular attachment (Figs 5).

\section{At 7.5 - 8 years of age of the cam- el:}

The hyoid bone increases in length and size and each part completes its ossification except the basihyoid which is still cartilaginous (Figs 7 ,

8). The cartilages which found among the ceratohyoid, the epihyoid and stylohyoid are diminishing in size (Figs 7, 8). The thyrohyoids become as long as the epihyoids and its free ends become ossified (Figs 7, 8).

\section{Discussion}

The hyoid bone can be divided into two parts. The first part supports the tongue and larynx and is regarded as the hyoid apparatus, equivalent that of the man. The second part is directed dorsally articulating with the temporal bone and is termed the suspensory apparatus (König and Liebich, 2004).

The basihyoid, the lingual process and the thyrohyoid of the horse are fused and may be compared to a spur or a fork with a very short handle. The thyrohyoid of the cattle don't fuse with the basihyoid except in old age (Hillmann, 1975).This result revealed that there is no separate center for the basihyoid of the hyoid bone of the camel but it is formed by the union of the rostral ends of the thyrohyoids.

The lingual process is missing in the hyoid bone of the camel, as supported by Smut and bezoidenhout (1987). The lingual process of the hyoid bone of the horse is thin and long while that of the cattle is short and tuberous (Hillmann, 1975). 
In camel, the epihyoids are twice as long as the ceratohyoids. The epihyoids of horse are small, wedgeshaped pieces interposed between the ceratohyoids and stylohyoids or fused with the stylohyoids while the epihyoids of cattle are almost as large as the ceratohyoids (Hillmann, 1975). The epihyoids are cylindrical in carnivores and are replaced by the epihyoid ligament in pigs (König and Liebich, 2004). In ruminant and horse, the stylohyoids articulate dorsally with the styloid process of the temporal bone, in carnivores with the mastoid process of the temporal bone and in the pig with the nuchal process of the squamous temporal bone (König and Liebich, 2004). In human, the hyoid bone is unique because it neither articulates with the skull nor any other bone in the human body (Scheuer and Black, 2000).

\section{Conclusions}

1- The hyoid bone develops from eight ossification centers; none of them complete its ossification before birth.

2- There is no separate center for the basihyoid of the hyoid bone of the camel but it is formed by the union of the rostral ends of the thyrohyoids.

3- The lingual process of the basihyoid is missing in the camel.

\section{References}

Atalgin, H., Kürtül, I., Bozkurt, E. U. (2007): Postnatal osteological development of the hyoid bone in the new zealand white rabbit. Veterinary Research Communications. 31 (6): 653-660.

Barone, R., Pavaux, C., Blin P. C. and Cuq, P. (1973): Atlas of Rabbit Anatomy, (Masson et Cie, Paris), 11-50.

Budras, K., Sack, W. O. and Röck, S. (2009): Anatomy of the horse. Fifth revised Edition. Schlütersche Verlagsgesellschaft. Hans-BöcklerAlle 7, 30173 Hannover.

Craigie, E. H. (1969): Practical Anatomy of the Rabbit, 8th ed, (University of Toronto Press, Toronto), 197-198.

El-Wishy, A. B., Hemeida, N. A., Omar, M. A., Mobarak, A. M., ElSayed, M. A. (1981): Functional changes in the pregnant camel with special reference to foetal growth. Br Vet J, 37:527-53

Hillmann, D. J., 1975: Skull. In: Sisson and Grossman's The Anatomy of the Domestic Animals, 5th ed. (R. Getty, ed). Philadelphia, PA: WB Saunders Co. 
Hilloowala, R. A. (1975): Comparative anatomical study of the hyoid apparatus in selected primates. Am. J. Anat. 142(3):367-84.

Koebke, J., 1978: Some observations on the development of the human hyoid bone. Anat. Embryol. 153: 279- 286.

König, H. \& Liebich, H. G. (2004): Veterinary Anatomy of Domestic Mammals. Schattauer, $\mathrm{GmbH}$, Stuttgart.

Popesko, P., Rajtowa, V. and Horak, J. (1992): A Colour Atlas of Anatomy of Small Laboratory Ani- mals, vol. I: Rabbit, Gunea Pig, (Wolfe Publishing, London), 120.

Rabigliata, D. S. (1924): The dentition of the camel. Govt. Press. Cairo, Egypt.

Scheuer, L. and Black, S. (2000): Developmental juvenile osteology. San Diego, Elsevier Academic Press.

Smut M. S. and Bezuidenhout A. J. (1987): Anatomy of the dromedary. Clarendon Press. Oxford.
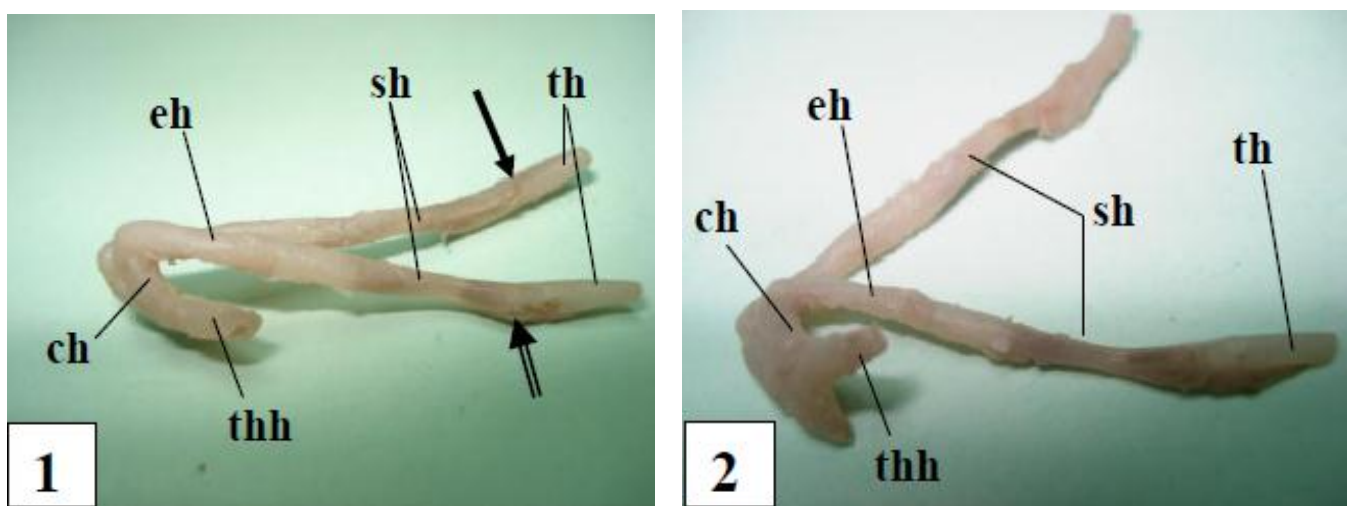

Fig (1): Lateral view of the hyoid bone of a fetal specimen with $40.5 \mathrm{~cm}$ CVR length shows that the thyrohyoids (thh), the ceratohyoids (ch) and the epihyoids (eh) are still in the cartilaginous form while the stylohyoids (sh) show ossification in its central part. Black arrow $=$ articular angle, open black arrow $=$ muscular angle, th $=$ tympanohyoid.

Fig (2): Ventro-lateral view of the hyoid bone of a fetal specimen with $40.5 \mathrm{~cm}$ CVR length shows that the thyrohyoids (thh) are short cylindrical rods of cartilage at this stage of development. $\mathrm{ch}=$ ceratohyoid, eh = epihyoid, $\mathrm{sh}=$ stylohyoid, th = tympanohyoid. 

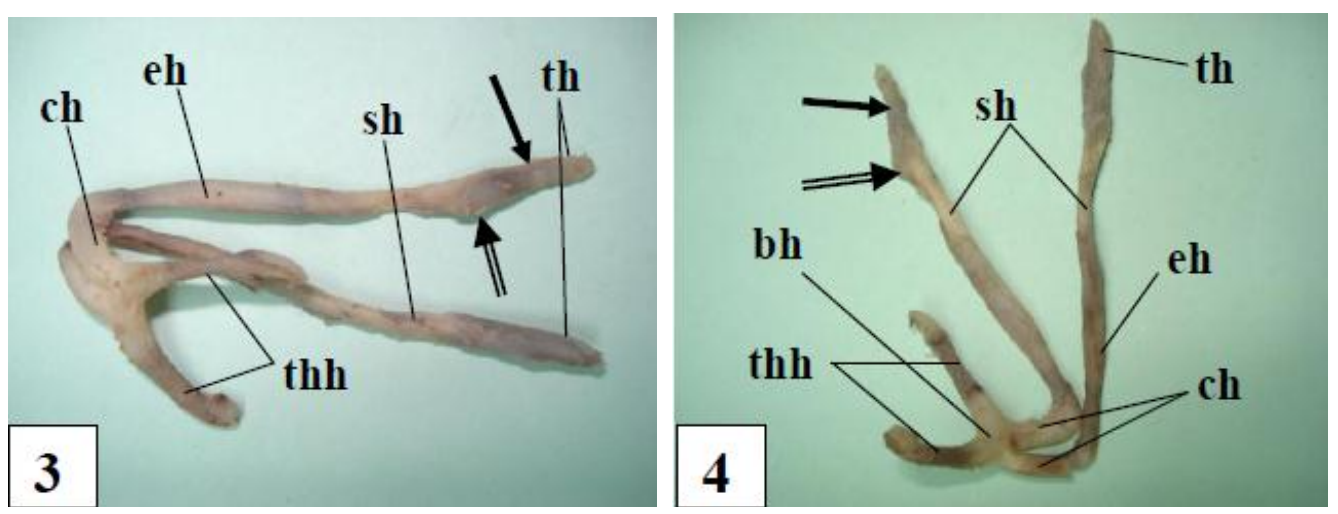

Fig (3): Ventro-lateral view of the hyoid bone of a fetal specimen with $80 \mathrm{~cm}$ CVR length shows that the ossification spreads to the thyrohyoids (thh), the ceratohyoids (ch), the epihyoids (eh). The articular (black arrow) and the muscular (open black arrow) angles become clear. $\mathrm{sh}=$ stylohyoid, th = tympanohyoid.

Fig (4): Dorso-lateral view of the hyoid bone of a fetal specimen with $80 \mathrm{~cm}$ CVR length shows that the basihyoid (bh) is formed by the union of the rostral ends of the thyrohyoids (thh) which are still cartilaginous. The articular (black arrow) and the muscular (open black arrow) angles become clear ch = ceratohyoid, eh = epihyoid, sh = stylohyoid, th = tympanohyoid.
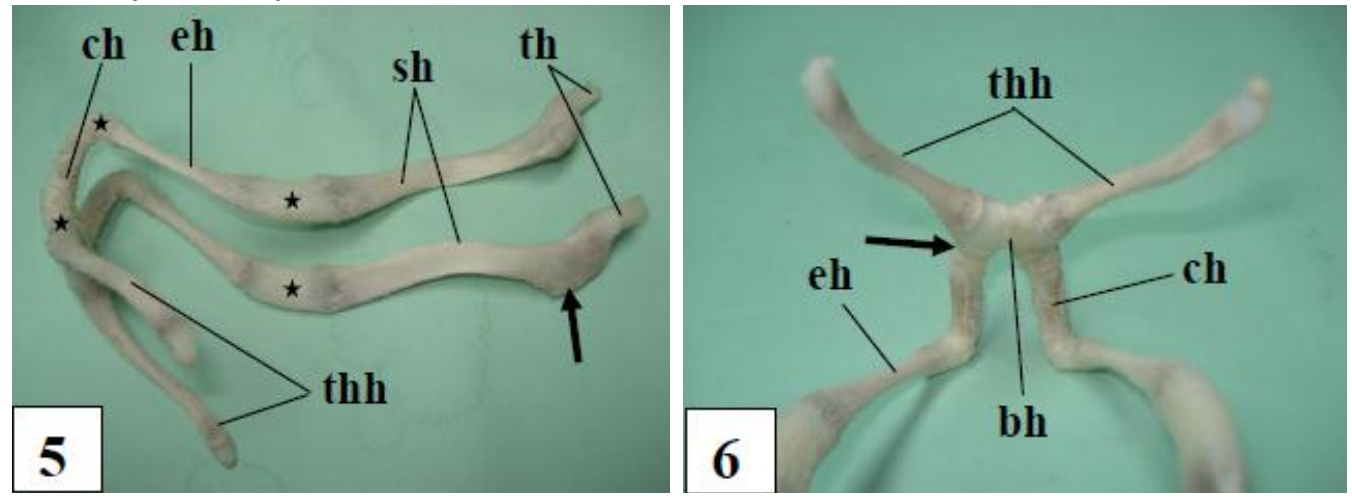

Fig (5): Lateral view of the hyoid bone of the camel, 3 years of age shows that the hyoid bone increases in length and size and each part is still separated from each other by a considerable rod of cartilage (black stars). The stylohyoids (sh) are slightly longer than the preceding bones and are curved medialwards. The muscular processes (black arrow) become thickened and rough for muscular attachment. ch = ceratohyoid, eh = epihyoid, thh = thyrohyoid, th = tympanohyoid.

Fig (6): Caudo-ventral view of the hyoid bone of the camel, 3 years of age shows that the basihyoid (bh) is still cartilaginous and its dorsal ends have concave facets which articulate with the ventral ends of the ceratohyoids (black arrow). ch = ceratohyoid, eh = epihyoid, thh = thyrohyoid. 

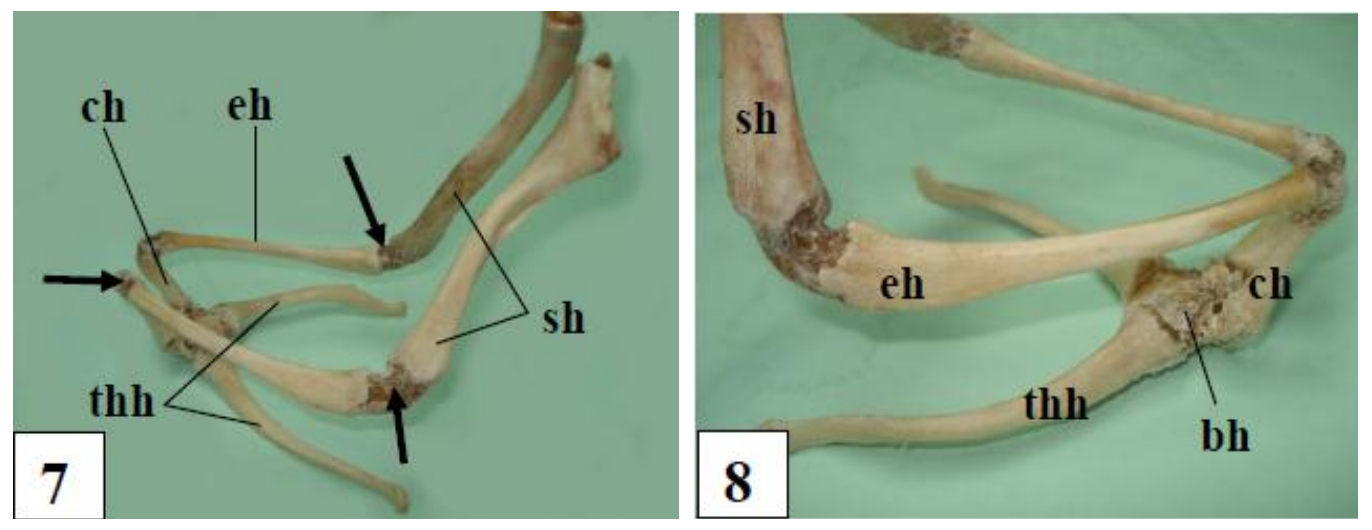

Fig (7): Dorso-lateral view of the hyoid bone of the camel, 7.5-8 years of age shows that the hyoid bone increases in length and size and each part of the hyoid bone completes its ossification. The cartilages which found among the ceratohyoid (ch), the epihyoid (eh) and stylohyoid (sh) are diminishing in size (black arrows). thh $=$ thyrohyoid.

Fig (8): Dorso-lateral view of the hyoid bone of the camel, 7.5-8 years of age shows that the basihyoid (bh) is still cartilaginous and the thyrohyoids (thh) become as long as the epihyoids (eh) and its free ends become ossified. $\mathrm{sh}=$ stylohyoid. $\mathrm{ch}=$ ceratohyoid. 